\title{
Effect of Dietary Supplementation of Wild Grape on the Antioxidative Potential of the Breast and Leg Meat of Broilers
}

\author{
Hae In Yong, Hyun Joo Kim, Samooel Jung, Dinesh D. Jayasena, \\ Young Sik Bae, Soo Kee Lee, and Cheorun Jo* \\ Department of Animal Science and Biotechnology, Chungnam National University, Daejeon 305-764, Korea
}

\begin{abstract}
This study investigated the effect of wild grape (Vitis coignetiae) dietary supplementation on the antioxidative potential and quality of the breast and leg meat of broilers. A total of 36 one-day-old male Cobb broiler chicks were obtained from a commercial hatchery, and randomly assigned to 9 pens with 4 birds per pen. Then, broilers were fed 3 different dietary supplementations, including $0 \%, 0.25 \%$, or $0.5 \%$ wild grape, for $2 \mathrm{wks}$ at the finishing period. After slaughtering, the total phenolic content, $\alpha, \alpha^{\prime}$-diphenyl- $\beta$-picryl-hydrazyl (DPPH) radical scavenging activity, 2 -thiobarbituric acid reactive substances (TBARS), and total cholesterol content of broiler breast and leg meat were measured. Higher total phenolic content was recorded in the leg meat of broilers fed the wild grape when compared with the control, while breast meat did not show any difference. Dietary supplementation of $0.25 \%$ and $0.5 \%$ wild grape significantly increased DPPH radical scavenging activity of both breast and leg meat. TBARS values of both breast and leg meat were decreased by supplementation of $0.5 \%$ wild grape during storage when compared to the control, except for the leg meat at day 7 . However, there was no significant difference found in total cholesterol content in both breast and leg meat. The results indicate that the antioxidative potential of broiler meat is improved by supplementing the diet with wild grape.
\end{abstract}

Key words: wild grape, antioxidative potential, lipid oxidation, total cholesterol content

\section{Introduction}

Since ancient times, meat has played a vital role in the human diet, mainly as an excellent source of protein with high biological value. In addition, meat and meat products are important sources of fat, essential amino acids, minerals, and vitamins (Biesalski, 2005). Chicken meat is well recognized as a nutritional and healthy animal food, due to its relatively low fat, calorie, and cholesterol content, as well as its relatively high concentration of polyunsaturated fatty acids and protein content (Lee et al., 2012; Liu et al., 2012). However, oxidation in meat and meat products is a major problem in the meat industry (Kang et al., 2012). Furthermore, chicken meat is more liable to lipid oxidation, and thereby to the development of "offflavors," because it contains higher levels of unsaturated fatty acids compared to red meat. This issue presents a major problem with respect to retaining the quality of

*Corresponding author: Cheorun Jo, Department of Animal Science and Biotechnology, Chungnam National University, Daejeon 305-764, Korea. Tel: 82-42-821-5774, Fax: 82-42825-9754, E-mail: cheorun@cnu.ac.kr chicken meat for longer periods of time.

For this reason, antioxidants are added to fresh and processed meat to delay the onset of oxidative processes and loss of meat quality. In effect, antioxidants extend the storage period of meat by inhibiting the initiation or propagation of oxidative chain reactions (Xiong et al., 1993). In general, natural antioxidants are preferentially used in many products in the food industry over synthetic antioxidants, such as butylated hydroxytoluene (BHT) and butylated hydroxyanisole (BHA), which may be carcinogenic to consumers (Branen, 1975; Huang et al., 2011; Reishe et al., 1998). Therefore, research in this field is now primarily focused on natural antioxidants, which ultimately provide higher consumer acceptability, palatability, safety, and potential to improve the functional aspects of meat (Brenes et al., 2008; Jo et al., 2009; Jung et al., 2010).

Recent studies have demonstrated the beneficial effect of plant originated phenolic compounds, which contain antioxidant potential via redox properties, in addition to having several beneficial actions on human health (Catherine et al., 1997; Fraga et al., 2010; Kafakaya, 2004). Grape and tea are of special interest as natural polyphenol 
antioxidants, due to their high phenolic compound content (Banon et al., 2007). These polyphenols are well known for their beneficial functions, such as the inhibition of lipid oxidation, cancer, or microbial growth, in addition to the suppression of blood pressure or atherosclerosis, prevention of diabetes, and the reduction of allergenicity (Byun et al., 2004; Catherine et al., 1996; Fraga et al., 2010; Mazza, 1998). Furthermore, the antioxidant potential of grape polyphenols has been confirmed in studies conducted using fish oil, frozen fish, cooked pork patties, and cooked turkey stored under retail display conditions (Banon et al., 2007). Previous studies have demonstrated that the negative outcome of lipid oxidation in chicken meat may be reduced by supplementing the diet of live chicken with antioxidants, such as medicinal herb mix and grape pomace (Jung et al., 2010).

Wild grape (Vitis coignetiae) is considered to be a rich source of mineral, dietary fiber, organic acids, water-soluble vitamins, and phenolic compounds, including resveratrol, epicatechin, catechin, procianidin, and anthocyanin (Cheon, 1999; Jeong et al., 2007; Kim et al., 2006). In a study conducted by Yoon and Kim (2007) on total phenolic compounds and antioxidant activity of fruits (including strawberry, kiwi, apple, and wild grape), wild grape contained the highest amount of phenolic compounds, and exhibited over twice the antioxidant activity of a grape cultivar (Vitis labrusca). In addition, feeding fermented wild grape by-products to pigs decreased the 2-thiobarbituric acid-reactive substances (TBARS) values and cholesterol content of pork, as well as increasing its color, taste, flavor, and juiciness (Park and Jung, 2005). Won (2009) reported that wild grape juice increased the antioxidative activity of the blood and liver of rats that were fed high oxidized lipids. Furthermore, Yong et al. (2012) recently reported an improvement in the quality and freshness of eggs from layers that were fed wild grape powder.

Thus, the objective of this study was to investigate the effect of providing wild grape as a dietary supplement on the antioxidative potential of broiler breast and leg meat.

\section{Materials and Methods}

\section{Preparation of animals and samples}

A total of 36 one-day-old male Cobb broiler chicks (Cobb strain) were obtained from a commercial hatchery, and randomly assigned to 9 pens with 4 birds per pen. During the entire experiment, broilers were housed under $24 \mathrm{~h}$ fluorescent lighting, standard temperature, humidity, and ventilation conditions, and had ad libitum access to water and food. The broiler chicks were fed a commercial broiler starter diet (0-6 d), then, fed grower diets (7-21 d). At the end of week 3 , broilers were reassigned to 3 different dietary treatments, and reared for a further 2 wks. Each treatment had 3 replicates, with 4 broilers in each replicate (total $n=36$ ). Dietary treatments consisted of a control (commercial finisher diet with no supplementation), and finisher diets supplemented with $0.25 \%$ (WG0.25 ), and $0.5 \%$ wild grape powder (WG-0.5), respectively.

At the end of the feeding trial, broilers from each pen were slaughtered, and the feathers and entrails (evisceration) were removed from the carcasses. Breast and leg meat were then dissected from each carcass, vacuum packaged, and stored in a deep freezer at $-50^{\circ} \mathrm{C}$ until the analysis.

\section{Measurement of antioxidative activity}

The meat samples $(3 \mathrm{~g})$ were homogenized (T25b, Ika Works (Asia), Sdn, Bhd, Malaysia) in $15 \mathrm{~mL}$ of distilled water at $16,000 \mathrm{rpm}$ for $20 \mathrm{~s}$. The samples were centrifuged (Union 32R, Hanil Co., Ltd., Korea) at 3,000 rpm for $10 \mathrm{~min}$, and then filtered through Whatman No. 1 filter paper (Whatman Ltd., England). Chloroform $(10 \mathrm{~mL})$ was added to the homogenates to remove fat, and the mixture was shaken 3 times. The mixture was then separated into lipids and aqueous supernatant by centrifugation (Union 32R, Hanil Co., Ltd., Korea) at 3,000 rpm for $10 \mathrm{~min}$. The supernatant was used for the analysis of total phenolic content and $\alpha, \alpha^{\prime}$-diphenyl- $\beta$-picryl-hydrazyl (DPPH) radical scavenging activity.

\section{Total phenolic content}

Total phenolic content was measured using the FolinCiocalteu method (Subramanian et al., 1965). A 0.1-mL aliquot was added to $0.2 \mathrm{~mL}$ Folin-Ciocalteu reagent and allowed to react for $1 \mathrm{~min}$. Sodium carbonate $(5 \%, 3 \mathrm{~mL})$ was added to the mixture and vortexed. The mixture was then incubated at $23^{\circ} \mathrm{C}$ in the dark for $2 \mathrm{~h}$. The absorbance was measured using a spectrophotometer (DU 530, Beckman Instruments Inc., USA) at $765 \mathrm{~nm}$. The natural phenolics were quantified using a standard curve generated for gallic acid, and were expressed as gallic acid equivalents.

\section{DPPH radical scavenging activity}

DPPH radical scavenging activity was estimated according to the method described by Jung et al. (2010). A $0.2-\mathrm{mL}$ aliquot was mixed with $0.8 \mathrm{~mL}$ distilled water 
and $1 \mathrm{~mL}$ of $0.2 \mathrm{mM}$ methanolic DPPH solution. For the control, the aliquot solution $(0.2 \mathrm{~mL})$ was replaced with distilled water. The mixture was vortexed and maintained at room temperature for $30 \mathrm{~min}$. The absorbance of the solution was measured using a spectrophotometer (Beckman Instruments Inc., USA) at $517 \mathrm{~nm}$. The percentage of DPPH radical scavenging was obtained from the following equation:

$$
\begin{aligned}
& \text { DPPH radical scavenging activity } \\
& =[1-(\text { absorbance of sample/absorbance of control })] \\
& \quad \times 100
\end{aligned}
$$

\section{2-Thiobarbituric acid-reactive substances (TBARS) value}

TBARS values of meat samples were analyzed after storage at $4^{\circ} \mathrm{C}$ for 0,3 , and $7 \mathrm{~d}$, according to the method of Jung et al. (2011). Nine milliliters distilled water and $50 \mu \mathrm{L}$ BHT (7.2\% in ethanol) were added to each meat sample (3 g). The mixture was homogenized (T25b, Ika Works (Asia), Sdn, Bhd, Malaysia) at 16,000 rpm for 20 s. The homogenate $(1 \mathrm{~mL})$ was transferred to a test tube, and then thiobarburic acid (TBA)/trichloroacetic acid (TCA) solution (20 mM TBA in 15\% TCA, $2 \mathrm{~mL}$ ) was added. The test tubes were heated in a water bath at $90^{\circ} \mathrm{C}$ for $15 \mathrm{~min}$, cooled in cold water, and then centrifuged (Union 32R, Hanil Co., Ltd., Korea) at 3,000 rpm for 10 min. The absorbance of the supernatant was measured using a spectrophotometer (Beckman Instruments Inc.) at $532 \mathrm{~nm}$. TBARS values were reported as mg malondialdehyde per kg meat.

\section{Cholesterol content}

Meat samples ( $1 \mathrm{~g})$ were mixed with $20 \mathrm{~mL}$ Folch solution (chloroform:methanol $=2: 1$ ), and separated into 2 layers by centrifugation (Union 32R, Hanil Co., Ltd., Korea) at 3,100 rpm for $5 \mathrm{~min}$. The chloroform layer containing total lipids was dehydrated using anhydrous $\mathrm{Na}_{2} \mathrm{SO}_{4}$, and the resulting solution was evaporated using nitrogen. Subsequently, $2 \mathrm{~mL}$ of $2 \mathrm{~N}$ ethanolic $\mathrm{KOH}$ was added to the sample, which was then placed in a $90^{\circ} \mathrm{C}$ water bath for $15 \mathrm{~min}$ for saponification. The aliquot was then cooled in cold water, and $1 \mathrm{~mL}$ of distilled water was added. Cholesterol in unsaponifiable fractions was extracted 3 times using $1 \mathrm{~mL}$ hexane. The resulting hexane aliquot was dried up to $1.5 \mathrm{~mL}$ using nitrogen, dehydrated using anhydrous $\mathrm{Na}_{2} \mathrm{SO}_{4}$, and injected into a gas chromatograph (GC-17A, Simazu, Japan). 5 $\alpha$-Cholestane (SigmaAldrich) was used as an internal standard. A split inlet (split ratio, 50:1) was used to inject the samples into a HP-5 capillary column $(30 \mathrm{~m} \times 0.25 \mathrm{~mm} \times 0.25 \mu \mathrm{m})$, and a ramped oven temperature was used $\left(200^{\circ} \mathrm{C}\right.$ for $5 \mathrm{~min}$, increased to $300^{\circ} \mathrm{C}$ at $10^{\circ} \mathrm{C} / \mathrm{min}$ ). The injector temperature was $270^{\circ} \mathrm{C}$, and the flame ionization detector temperature was $300^{\circ} \mathrm{C} . \mathrm{N}_{2}$ served as the carrier gas at a constant flow rate of $2.0 \mathrm{~mL} / \mathrm{min}$.

\section{Statistical analysis}

Statistical analysis was performed using one-way analysis of variance (ANOVA). Differences among the mean were determined using Duncan's multiple range test with the significance defined as $p<0.05$.

\section{Results and Discussion}

\section{Antioxidative activity and lipid oxidation}

The total phenolic content of WG-0.5 was $0.75 \mathrm{mg} / \mathrm{g}$ for broiler leg meat, which was significantly higher compared to the other treatments (Table 1). The breast meat exhibited higher total phenolic content (1.13-1.14 mg/g) compared to the leg meat $(0.69-0.75 \mathrm{mg} / \mathrm{g})$, which was due to the low fat content of breast meat compared to leg meat (Jo et al., 2009). However, no significant difference in the total phenolic content of breast meat was found among the 3 treatments. These results indicate that WG0.5 increases the antioxidative activity of broiler leg meat.

To evaluate the antioxidative effect of wild grape on broiler meat, DPPH radical scavenging activity was determined (Table 2). The breast and leg meat of broilers fed WG-0.25 and WG-0.5 produced significantly higher DPPH values compared to the control. This finding indicates the utility of wild grape as a dietary supplement in which electron donors neutralize free radicals.

Table 3 shows the TBARS values of the breast and leg meat of broilers fed wild grape dietary supplements after

Table 1. Total phenolic contents $(\mathrm{mg} / \mathrm{g})$ of the meat from broilers fed wild grape

\begin{tabular}{lcc}
\hline \hline Treatment $^{1)}$ & Breast meat & Leg meat \\
\hline Control & 1.13 & $0.69^{\mathrm{b}}$ \\
WG-0.25 & 1.13 & $0.66^{\mathrm{b}}$ \\
WG-0.5 & 1.14 & $0.75^{\mathrm{a}}$ \\
SEM $^{2)}$ & 0.014 & 0.013
\end{tabular}

${ }^{1)}$ Control, commercial finisher diet; WG-0.25, finisher diet with dietary supplementation of $0.25 \%$ wild grape; WG- 0.5 , finisher diet with dietary supplementation of $0.5 \%$ wild grape

${ }^{2)}$ Standard error of means $(n=9)$

${ }^{a, b}$ Means with different letters within the same column differ significantly $(p<0.05)$. 
Table 2. $\alpha, \alpha^{\prime}$-Diphenyl- $\beta$-picryl-hydrazyl radical scavenging activity (\%) of the meat from broilers fed wild grape

\begin{tabular}{lcc}
\hline \hline Treatment ${ }^{1)}$ & Breast meat & Leg meat \\
\hline Control & $15.63^{\mathrm{b}}$ & $23.66^{\mathrm{b}}$ \\
WG-0.25 & $19.51^{\mathrm{a}}$ & $27.74^{\mathrm{a}}$ \\
WG-0.5 & $18.60^{\mathrm{a}}$ & $27.95^{\mathrm{a}}$ \\
SEM $^{2)}$ & 0.438 & 0.947 \\
\hline
\end{tabular}

${ }^{1)}$ Control, commercial finisher diet; WG-0.25, finisher diet with dietary supplementation of $0.25 \%$ wild grape; WG- 0.5 , finisher diet with dietary supplementation of $0.5 \%$ wild grape

${ }^{2)}$ Standard error of means $(n=9)$

${ }^{\mathrm{a}, \mathrm{b}}$ Means with different letters within the same column differ significantly $(p<0.05)$.

Table 3. 2-Thiobarbituric acid reactive substances (mg malondialdehyde/kg meat) values of meat from broilers fed wild grape

\begin{tabular}{|c|c|c|c|c|}
\hline \multirow{2}{*}{ Treatment $^{1)}$} & \multicolumn{4}{|c|}{ Storage (d) } \\
\hline & 0 & 3 & 7 & SEM $^{2)}$ \\
\hline \multicolumn{5}{|c|}{ Breast meat } \\
\hline Control & $0.39^{\mathrm{cx}}$ & $0.52^{\mathrm{bx}}$ & $0.65^{\mathrm{ax}}$ & 0.011 \\
\hline WG- 0.25 & $0.38^{\mathrm{cx}}$ & $0.48^{\mathrm{bxy}}$ & $0.62^{\mathrm{ax}}$ & 0.025 \\
\hline WG-0.5 & $0.30^{\text {by }}$ & $0.43^{\text {ay }}$ & $0.44^{\mathrm{ay}}$ & 0.010 \\
\hline SEM $^{2)}$ & 0.010 & 0.016 & 0.022 & \\
\hline \multicolumn{5}{|c|}{ Leg meat } \\
\hline Control & $0.55^{\mathrm{cx}}$ & $0.82^{b x}$ & $0.88^{\mathrm{ax}}$ & 0.012 \\
\hline WG- 0.25 & $0.40^{\text {by }}$ & $0.82^{\mathrm{ax}}$ & $0.88^{\mathrm{ax}}$ & 0.071 \\
\hline WG-0.5 & $0.38^{\text {cy }}$ & $0.52^{\text {by }}$ & $0.75^{\mathrm{ax}}$ & 0.025 \\
\hline SEM $^{2)}$ & 0.012 & 0.061 & 0.044 & \\
\hline
\end{tabular}

${ }^{1)}$ Control, commercial finisher diet; WG-0.25, finisher diet with die]tary supplementation of $0.25 \%$ wild grape; WG- 0.5 , finisher diet with dietary supplementation of $0.5 \%$ wild grape

${ }^{2)}$ Standard error of means $(n=9)$

${ }^{\mathrm{a}-\mathrm{c}}$ Means with different letters within the same row differ significantly $(p<0.05)$.

${ }^{\mathrm{x}, \mathrm{y}}$ Means with different letters within the same column differ significantly $(p<0.05)$.

storage at $4^{\circ} \mathrm{C}$ for 0,3 , and $7 \mathrm{~d}$. Generally, TBARS values increased with storage time, due to the auto-oxidation of fat in the presence of oxygen. During the entire storage period, the TBARS value of the breast meat from broilers fed WG- 0.5 was significantly lower compared to the other 2 treatments. The leg meat from the broilers fed WG- 0.25 and WG- 0.5 exhibited significantly lower TBARS values compared to the control during initial stage of storage. After $3 \mathrm{~d}$ of storage, the lowest $(p<0.05)$ TBARS value was exhibited by leg meat from the WG-0.5 treatment. However, there was no significant difference among treatments for TBARS values of the leg meat after $7 \mathrm{~d}$ of storage. The WG- 0.5 treatment was the most effective at preventing lipid oxidation, except for leg meat stored for $7 \mathrm{~d}$.
The presence of polyphenols in meat is closely related to total antioxidant capacity (Prasad et al., 2009). For instance, broilers fed a dietary medicinal herb extract mix exhibited higher total phenols and DPPH values at day 0 of storage compared to the control, indicating that the antioxidant activity of medicinal plants is transferred to broilers (Jang et al., 2008; Jo et al., 2009). Furthermore, the dietary supplementation of grape pomace was shown to improve antioxidant activity in chicken (Goni et al., 2007).

Dietary phenolic sources, such as fermented wild grape, grape seed extract, and grape pomace also decrease TBARS values in pork, lamb meat, and chicken (Goni et al., 2007; Jeronimo et al., 2012; Park and Jung, 2005), with these results also being supported by the present study. This is because polyphenols donate hydrogen and electrons to free radicals, which results in oxidative chain reactions delaying lipid oxidation (Fraga et al., 2010). Another reason why lipid oxidation is inhibited is related to corticosterone causing a decline in oxidative stress (Ohtsuka et al., 1998). Grape leaf extract and tea polyphenol have been reported to induce oxidative stress in rats and broilers, with broilers exhibiting low TBARS values compared to the control (Eid et al., 2003; Pari and Suresh, 2008).

The results of this study indicate that the dietary supplementation of wild grape might enhance antioxidant activity and delay lipid oxidation in broiler meat.

\section{Cholesterol content}

Cholesterol is an important component of human cell membranes; however, foods with high cholesterol contests might lead to cardiovascular diseases (Kang and Song, 1997; Park and Jung, 2005). Cholesterol is synthesized in the liver through acetyl-CoA, 3-hydroxy-3-methylglutaryl coenzyme A (HMG-CoA), mevalonate, squalene, lanosterol, and over 30 intermediate substances, to maintain blood cholesterol concentrations (Kim, 1992; Park et al., 1997). It has been reported that dietary fiber, vitamin $\mathrm{C}$, and polyphenols including catechin and quercetin inhibit the synthesis of cholesterol or increase the extraction of bile acid, which is the only pathway for cholesterol excretion (Kang and Song, 1997; Kwon et al., 1993; Paolisso et al., 1995; Yokota et al., 1996). Fermented wild gape by-product, Eosungcho powder, and onion peel contain large amounts of antioxidants, which have been shown to decrease the cholesterol content of pork meat by delaying lipid absorption (Joo et al., 1999; Kang et al., 2006; Park and Jung, 2005). However, the cholesterol 
Table 4. Total cholesterol contents $(\mathrm{mg} / \mathrm{g})$ of the meat from broilers fed wild grape

\begin{tabular}{ccc}
\hline \hline Treatment $^{1)}$ & Breast meat & Leg meat \\
\hline Control & 0.50 & 1.33 \\
WG-0.25 & 0.37 & 1.27 \\
WG-0.5 & 0.36 & 1.34 \\
SEM $^{2)}$ & 0.034 & 0.078
\end{tabular}

${ }^{1)}$ Control, commercial finisher diet; WG-0.25, finisher diet with dietary supplementation of $0.25 \%$ wild grape; WG- 0.5 , finisher diet with dietary supplementation of $0.5 \%$ wild grape

${ }^{2)}$ Standard error of means $(n=9)$

content of breast and leg meat was not significantly affected by wild grape dietary supplementation (Table 4). Similar findings to our study have been reported for green tea by-products, wild grape juice, and wild grape, which were found to have no effect on the cholesterol content of chicken, blood cholesterol content of rats fed high oxidized lipid, or chicken eggs (Yang et al. 2003; Yong et al., 2012; Won, 2009).

The extraction of bile acid contributes towards reducing the amount of cholesterol in the body. However, this effect is not entirely related to the reabsorption of bile acids. Triglycerides, cholesterol, and other nutritional ingredients also have an additional effect (Kang and Song, 1997). Hence, further studies are required to better understand the synthesis of cholesterol and the factors that influence the cholesterol content of broiler meat.

In conclusion, the present study demonstrated the bioavailability of wild grape as an antioxidative dietary source for broilers.

\section{Acknowledgement}

This work was supported by a grant from the NextGeneration BioGreen 21 Program (No. PJ0081330), Rural Development Administration, Republic of Korea.

\section{References}

1. Banon, S., Diaz, P., Rodriguez, M., Garrido, M. D., and Price, A. (2007) Ascorbate, green tea and grape seed extracts increase the shelf life of low sulphite beef patties. Meat Sci. 77, 626633.

2. Biesalski, H. K. (2005) Meat as a component of a healthy diet are there any risks or benefits if meat is avoided in the diet? Meat Sci. 70, 509-524.

3. Branen, A. L. (1975) Toxicology and biochemistry of butylated hydroxyanisole and butylated hydroxytoluene. J. Am. Oil Chem. Soc. 52, 59-63.

4. Brenes, A., Viveros, A., Goni, I., Centeno, C., Sayago-Ayerdy,
S. G., Arija, I., and F. Saura-Calixto, F. (2008) Effect of grape pomace concentrate and vitamin $\mathrm{E}$ on digestibility of polyphenols and antioxidant activity in chickens. Poultry Sci. 87, 307-316.

5. Byun, M. W., Jo, C., Lee, J. W., Jo, S. K., and Kim, K. S. (2004) Application of radiation technology to develop green tea leaf as a natural resource for the cosmetic industry. Radiat. Phys. Chem. 71, 485-487.

6. Catherine, R. E., Miller, N., and Paganga, G. (1997) Antioxidant properties of phenolic compounds. Trends Plant Sci. 2, 152-159.

7. Catherine, R. E., Miller, N., and Paganga, G. (1996) Structure-Antioxidant activity relations of flavonoids and phenolic acids. Free Radical Biol. Med. 20, 933-956.

8. Cheon, K. B. (1999) Screening of antioxidant from Vitis Coignetae, Vitis Vinifera L. and comparison of its antioxidant activity. MS Thesis. Kon-Kuk University, Seoul.

9. Eid, Y. Z., Ohtsuka, A., and Hayashi, K. (2003) Tea polyphenols reduce glucocorticoid-induced growth inhibition and oxidative stress in broiler chickens. Br. Poult. Sci. 44, 127132.

10. Fraga, C. G., Galleano, M., Verstraeten, S. V., and Oteiza. P. I. (2010). Basic biochemical mechanisms behind the health benefits of polyphenols. Mol. Aspects Med. 31, 435-445.

11. Goni. I., Brenes, A., Centeno, C., Viveros, A., Saura-Calixto, F., Rebole, A., Arija, I., and Estevez, R. (2007) Effect of dietary grape pomace and vitamin $\mathrm{E}$ on growth performance, nutrient digestibility, and susceptibility to meat lipid oxidation in chickens. Poultry Sci. 86, 508-516.

12. Huang, B., He, J., Ban, X., Zeng, H., Yao, X., and Wang, Y. (2011) Antioxidant activity of bovine and porcine meat treated with extracts from edible lotus (Nelumbo nucifera) rhizome knot and leaf. Meat Sci. 87, 46-53.

13. Jang, A., Liu, X. D., Shin, M. H., Lee, B. D., Lee, S. K., Lee, J. H., and Jo. C (2008) Antioxidative potential of raw breast meat from broiler chicks fed a dietary medicinal herb extract mix. Poultry Sci. 87, 2382-2389.

14. Jeong, H. J., Park, S. B., Kim, S., and Kim, H. K. (2007) Total polyphenol content and antioxidative activity of wild grape (Vitis coignetiae) extracts depending on ethanol concentrations. J. Korean Soc. Food. Sci. Nutr. 36, 1491-1496.

15. Jeronimo, E., Alfaia, C. M. M., Alves, S. P., Dentinho, M. T. P., Prates, J. A. M., Vasta, V., Santos-Silva, J., and Bessa, R. J. B. (2012) Effect of dietary grape seed extract and Cistus ladanifer L. in combination with vegetable oil supplementation on lamb meat quality. Meat Sci. 92, 841-847.

16. Jo, C., Jang, A., Jung, S., Choe, J. H., Kim, B., and Lee, K. H. (2009) Effect of dietary herb extract mix on antioxidative activity of chicken thigh meat. J. Korean Soc. Food Sci. Nutr. 38, 302-308.

17. Joo, S. T., Hur, S. J., Lee, J. I., Kim, D. H., Ha, Y. R., and Park, G. B. (1999) Influence of dietary onion peel on lipid oxidation, blood charcteristics and antimutagenicity of pork during storage. J. Anim. Sci.Technol. 41, 671-678.

18. Jung, S., Choe, J. H., Kim, B., Yun, H., Kruk, Z. A., and Jo, C. (2010) Effect of dietary mixture of gallic acid and linoleic 
acid on antioxidative potential and quality of breast meat from broilers. Meat sci. 86, 520-526.

19. Jung, Y., Jeon, H. J., Jung, S., Choe, J. H., Lee, J. H., Heo, K. N., Kang, B. S., and Jo, C. (2011) Comparison of quality traits of thigh meat from Korean native chickens and broilers. Korean J. Food Sci. An. 31, 684-692.

20. Kafakaya, S. (2004) Bioavailability of phenilic compounds. Crit. Rev. Food Sci. Nutr. 44, 453-464.

21. Kang, M. J., Joo, J. C., Shim, J. H., Choi, S. Y., and Seung, M. Y. (2006) The effect of feeding Houttuynia cordata thunb on cholesterol and cholesterol oxides of pork lion's. J. Life Sci. 16, 1029-1035.

22. Kang, H. J. and Song, Y. S. (1997) Dietary fiber and cholesterol metabolism. J. Korean Soc. Food Sci. Nutr. 26, 358369.

23. Kang, M., Kim, H. J., Jang, A., Gam, D. K., Yun, G. S., and Jo, C. (2012) Effect of dietary supplementation of quercetin on antioxidant activity and meat quality of beef cattle. $C N U$ J. Agric. Sci. 39, 61-68.

24. Kim, J. W. and Park, S. Y. (2001) The Perception and consumption pattern of broiler chicken in Korea. Korean $J$. Poult. Sci. 28, 193-205.

25. Kim, N. Y., Choi, J. H., Kim, Y. G., Jang, M. Y., Moon, J. H., Park, G. H., and Oh, D.H. (2006) Isolation and Identification of an Antioxidant Substance from Ethanol Extract of Wild Grape (Vitis coignetiea) Seed. Korean J. Food Sci. Technol. 38, 109-113

26. Kim, S. W. (1992) Inhibitory effects of bile acids on the cholesterol biosynthesis in cultured hepatocytes. J. Korean Soc. Food Sci. Nutr. 21, 496-501.

27. Kwon, M. S., Choi, J. S., and Byun, D. S. (1993) Effect of flavonoid $(+)$-catechin as stabilizer in rat fed fresh and peroxidized fish oil. J. Korean Soc. Food Nutr. 22, 367-514.

28. Lee, K. H., Jung, S., Kim, H. J., Kim, I. S., Lee, J. H., and Jo, C. (2012) Effect of dietary supplementation of the combination of gallic and linoleic acid in thigh meat of broilers. Asian-Aust. J. Anim. Sci. 25, 1641-1648.

29. Liu, X. D., Jayasena, D. D., Jung, Y., Jung, S., Kang, B. S., Heo, K. N., Lee, J. H., and Jo, C. (2012) Differential proteome analysis of breast and thigh muscles between Korean native chickens and commercial broilers. Asian-Aust. J. Anim. Sci. 25, 895-902.

30. Subramanian, K. N., Padmanaban, G., and Sarma, S. (1965) Folin-Ciocalteu reagent for the estimation of siderochromes. Anal. Biochem. 12, 106-112.

31. Mazza, G. (1998) Functional foods: Biochemical \& Processing Aspects. Technomic Publishing Company Inc., PA, USA.

32. Prasad, K., Yang, B., Yang, S., Chen, Y., Zhao, M., and Ashraf, M. (2009) Identification of phenolic compounds and appraisal of antioxidant and antityrosinase activities from litchi (Litchi sinensis Sonn.) seeds. Food Chem. 116, 1-7.

33. Ohtsuka, A., Ohtani, T., Horiguchi, H., Kojima, H., and Hayashi, K. (1998) Vitamin E reduces glucocorticoid induced growth inhibition and lipid peroxidation in rats. J. Nutr. Sci. 44, 237247.

34. Paolisso, G., Balbi, V., Volpe, C., Varricchio, G., Gambardella, A., Saccomanno, F., Ammendola, S., Varricchio, M., and D' Onofrio, F. (1995) Metabolic benefits deriving from chronic vitamin $\mathrm{C}$ supplementation in aged non-insulin dependent diabetics. J. Am. Coll. Nutr. 14, 387-392.

35. Pari, L. and Suresh, A. (2008) Effect of grape (Vitis vinifera L.) leaf extract on alcohol induced oxidative stress in rats. Food Chem. Toxicol. 46, 1627-1634.

36. Park, J. R., Park, J. C., Choi, S. H. (1997) Screening and characterization of anticholesterogenic substances from edible plant extracts. J. Korean Soc. Food Sci. Nutr. 26, 236-241.

37. Park, K. S. and Jung, I. C. (2005) Quality and palatability of pork meats fed with fermented wild grape by-product. $J$. East Asian Soc. Diet. Life 33, 121-126.

38. Reishe, D. W., Lillard, D. A., and Eitenmiller, P. R. (1998) Antioxidants in food lipids. In: Chemistry, Nutrition and Biotechnology. Ahoh CC and Min DB (eds) Marcel Dekker, Inc., NY, pp. 423-448.

39. Won, H. R. (2009) Effect of wild grape juice on lipid metabolism and antioxidaive activity in rat fed high oxidized lipid. Korean J. Comm. Living Sci. 20, 223-230.

40. Xiong, Y. L., Decker, E. A., Robe, G. H., and Moody, W. G. (1993) Gelation of crude myofibrillar protein isolated from beef-heart under antioxidative conditions. J. Food Sci. 58, 1241-1244.

41. Yang, C. J., Yang, I. Y., Oh, D. H., Bae, I. H., Cho, S. G., Kong, I. G., Uuganbayar, D., Nou1, I. S., and Choi K. S. (2003) Effect of green tea by-product on performance and body composition in broiler chicks. Asian-Aust. J. Anim. Sci. 16, 867-872.

42. Yokota, T., Hattori, T., Ohishi, H., Hasegawa, K., and Watanabe, K. (1996) The effect of antioxidant containing fraction from fermented soybean food on atherosclerosis development in cholesterol fed rabbits. LWT-Food Sci. Technol. 29, 751-755.

43. Yong, H. I., Kim, H. J., Jung, S., Kang, M., Bae, Y. S., and Jo, C. (2012) Effect of dietary supplementation of wild grape (Vitis coignetiae) on egg quality. CNU J. Agric. Sci. 39, 371376.

44. Yoon, K. E. and Kim, A. (2007) Total poly-phenol compounds and anti-oxidant activity in horticultural crops. $J$. Korean Soc. People Plants Environ. 10, 74-83.

(Received 2012.11.5/Revised 2013.1.24/Accepted 2013.2.18) 